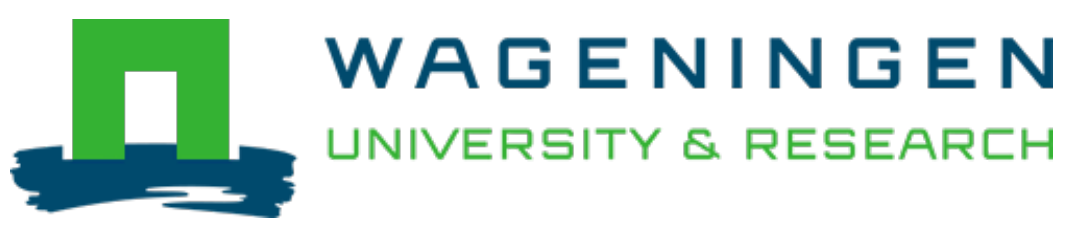

\title{
Modelling the effect of food composition on antimicrobial compound absorption and degradation in an active packaging
}

\author{
Journal of Food Engineering \\ Bahmid, Nur Alim; Dekker, Matthijs; Fogliano, Vincenzo; Heising, Jenneke \\ https://doi.org/10.1016/j.jfoodeng.2021.110539
}

This article is made publicly available in the institutional repository of Wageningen University and Research, under the terms of article $25 \mathrm{fa}$ of the Dutch Copyright Act, also known as the Amendment Taverne. This has been done with explicit consent by the author.

Article 25 fa states that the author of a short scientific work funded either wholly or partially by Dutch public funds is entitled to make that work publicly available for no consideration following a reasonable period of time after the work was first published, provided that clear reference is made to the source of the first publication of the work.

This publication is distributed under The Association of Universities in the Netherlands (VSNU) 'Article $25 \mathrm{fa}$ implementation' project. In this project research outputs of researchers employed by Dutch Universities that comply with the legal requirements of Article $25 \mathrm{fa}$ of the Dutch Copyright Act are distributed online and free of cost or other barriers in institutional repositories. Research outputs are distributed six months after their first online publication in the original published version and with proper attribution to the source of the original publication.

You are permitted to download and use the publication for personal purposes. All rights remain with the author(s) and / or copyright owner(s) of this work. Any use of the publication or parts of it other than authorised under article $25 \mathrm{fa}$ of the Dutch Copyright act is prohibited. Wageningen University \& Research and the author(s) of this publication shall not be held responsible or liable for any damages resulting from your (re)use of this publication.

For questions regarding the public availability of this article please contact openscience.library@,wur.nl 


\title{
Modelling the effect of food composition on antimicrobial compound absorption and degradation in an active packaging
}

\author{
Nur Alim Bahmid ${ }^{\mathrm{a}, \mathrm{b}}$, Matthijs Dekker ${ }^{\mathrm{a}}$, Vincenzo Fogliano ${ }^{\mathrm{a}}$, Jenneke Heising ${ }^{\mathrm{a},}$ \\ ${ }^{a}$ Food Quality and Design Group, Wageningen University and Research, P.O. Box 17, 6700 AA, Wageningen, The Netherlands \\ ${ }^{\mathrm{b}}$ Agricultural Product Technology Department, Agriculture and Forestry Faculty, Universitas Sulawesi Barat, Majene, 91412, Indonesia
}

\section{A R T I C L E I N F O}

\section{Keywords:}

Allyl isothiocyanate

Mass transfer

Absorption

Multiresponse kinetic

Kinetic modelling

Antimicrobial packaging

\begin{abstract}
A B S T R A C T
This study aims to comprehensively describe the rate of AITC release, absorption, and degradation in the packaging system by using multiresponse kinetic modelling. The effects of food composition and temperature on allyl isothiocyanates (AITC) partitioning in an antimicrobial packaging system were investigated. A higher protein content in the food caused a higher AITC concentration in the headspace, which can be explained by a lower mass transfer coefficient of AITC transfer from the headspace into the food matrix. A higher fat content in the food matrix caused a lower AITC concentration in the headspace, which can be explained by the fat stimulating AITC partitioning into the food matrix. At a lower temperature AITC is more stable in the headspace and food matrix. The results can be used to optimize the design of a packaging system with an AITC concentration tailored to the packed food product.
\end{abstract}

\section{Introduction}

Mustard seeds can be used as a natural source of AITC. Mustard seeds contain a high content of the glucosinolate sinigrin, which is a precursor of allyl isothiocyanate (AITC) (Rangkadilok et al., 2002; Saladino et al., 2017). AITC is formed from the enzymatic hydrolysis of sinigrin by the endogenous enzyme myrosinase (Cools and Terry, 2018; Hanschen et al., 2018). The sinigrin and myrosinase are located in distinct cells in the seeds, respectively in S-cells and myrosin cells (Kissen et al., 2009; Nakano et al., 2014). Once the cell tissues of mustard seeds are damaged by physical disruptions or by fat extraction for example, myrosinase is activated by moisture to hydrolyze sinigrin to generate AITC (Dekker et al., 2009). The mechanism of AITC formation in the mustard seeds shows a potential application of the mustard seeds as a natural carrier to release AITC into a packaging headspace to effectively inhibit microbial growth in foods (Bahmid et al., 2020a).

The antimicrobial effect of AITC against a variety of foodborne and spoilage bacteria depends on the concentration in the headspace (Aguilar-González et al., 2015; Clemente et al., 2016). A controlled release of AITC is important to reach a minimum headspace AITC concentration that is sufficient to inhibit bacteria for a prolonged time. In previous research, smaller particles $(50-100 \mu \mathrm{m})$ of mustard seeds containing $0 \%$ fat content released a higher AITC content to the headspace (Bahmid et al., 2020b). However, the presence of a (model) food in the food package causes the AITC released from ground mustard seeds to partition between the headspace and the packaged (model) food (Liu and Yang, 2010). The partition might consequently reduce the AITC concentration in the headspace, where the AITC more effectively inhibits the surface bacteria than bacteria growing inside the (model) foods due to interactions with the food components.

Food is a complex system, which contains a variety of components. For the application of AITC in food packaging, food components, like fat and proteins, might chemically and/or physically interact with the AITC absorbed into the food products, and then reduce the antimicrobial activity against spoilage bacteria. The AITC concentration can be affected by the presence of fat due to the solubility of AITC in the lipid phase (Keppler and Schwarz, 2017; Liu and Yang, 2010). In the presence of proteins, AITC can covalently bind amino acids, like $\beta$-lactoglobulin from whey protein isolate (Ersöz and Dudak, 2020; Holley and Patel, 2005; Kawakishi and Kaneko, 1987; Keppler et al., 2018; Kuhn et al., 2018). AITC can also react with (di)sulfide groups in proteins and with free amino acids, like lysine, glycine, and arginine to produce reaction products, such as allylamine and allyl thiourea (Cejpek et al., 2000; Winther and Nielsen, 2006). The possible interaction between food components and AITC is important to study to avoid a quick reduction of AITC concentration in the headspace of the packaging and to retain

\footnotetext{
* Corresponding author.

E-mail address: jenneke.heising@wur.nl (J. Heising).
} 
antimicrobial inhibition against spoilage bacteria growing in the food surface (Kurek et al., 2017). Besides the food composition, the storage temperature that will influence AITC volatility and stability will have an effect on the effective AITC concentration in the headspace and the food (Liu and Yang, 2010).

To understand the mechanisms of the partition of AITC in the packaging, multiresponse kinetic modelling can be used as a powerful tool by fitting an established model to multiple interlinked response data (Quintas et al., 2007). Our previous study (Bahmid et al., 2021) applied the multiresponse kinetic model to describe the AITC formation in the seeds, release to the headspace, and degradation well. However, this study excluded the (model) food that can absorb AITC and cause partitioning between the headspace and the packed food. Also, the effect of temperature on the model parameters was not yet investigated. It is therefore important to describe the AITC partition between the headspace and the (model) food of different compositions and at different temperatures, so that all important steps of the mass transfer mechanism of AITC in a designed packaging system can be described.

This study aimed therefore to describe the mass transfer of AITC from the headspace into the food matrix and its degradation in both the headspace and the food matrix using the multiresponse kinetic model. The effects of the composition of a packed food and storage temperature on the AITC partitioning in the antimicrobial packaging system were investigated. These results provide a better understanding of the mass transfer and reactions of antimicrobial compounds in a package with a (model) food and can be used in the design of an antimicrobial package that contains the desired concentration of the AITC in the package headspace for improving microbial inhibition in different foods.

\section{Materials and method}

\subsection{Materials}

Mustard seeds (Brassica juncea) were purchased from Natuurproduct. com, Jacob Hooy Brown Mustard seeds. Whey protein isolate (WPI; $\geq 90 \%(\mathrm{w} / \mathrm{w})$ ) was purchased from Davisco Foods International and menhaden fish oil was purchased from Brevoortia Sigma-Aldrich Corporation. Other chemicals used in this study were analytical grade and purchased from Sigma Aldrich or Merck.

\subsection{Samples preparation}

\subsubsection{Ground defatted mustard preparation}

Mustard seeds were freeze-dried for 2 days using an Alpha 2-4 LD plus freeze-dryer (Martin Christ freeze-dryers) coupled to an RZ 6 rotary vane pump (Vacuumbrand $\mathrm{GmbH}$ ). Thereafter the seeds were stored in a desiccator to ensure full hydration. After freeze-drying, the samples were ground and milled using a freezer-mill (6875D Freezer/Mill $\AA$, SPEX SamplePrep). Particle sizes of the ground mustard seeds were determined using a sieve machine (Fritsch Analysette) and seeds $<100$ $\mu \mathrm{m}$ were used. The samples were then fully defatted using Soxhlet extraction for $6 \mathrm{~h}$. The ground seeds were collected and stored in a desiccator containing limps of silica gel for 1 day to remove water or solvent left in the seeds and to prevent the pre-hydrolysis of sinigrin due to moisture uptake. Samples were stored in the freezer at $-20{ }^{\circ} \mathrm{C}$ till usage.

\subsubsection{Protein- and carbohydrate-based food matrix preparation}

Whey protein isolates (WPI) were used to investigate the AITC absorption in the protein-based matrix. The amount of WPI was added to certain volumes of MilliQ water to reach the desired percentages of protein $(0,2.5,5,10,15$, and $20 \% \mathrm{w} / \mathrm{v})$. The WPI was then dissolved in water by using a magnetic stirrer for $2 \mathrm{~h}$.

To confirm the effects of viscosity of the food matrix on the AITC absorption rate, a food matrix with a varying viscosity was made. Methylcellulose at different concentrations $(0,2.5$, and $5 \% \mathrm{w} / \mathrm{v})$ was used to vary the viscosity of the food matrix. The amounts of methylcellulose were added to MilliQ water to reach the desired concentration and then dissolved by using a magnetic stirrer for $24 \mathrm{~h}$ until being welldissolved.

\subsubsection{Fat-based food matrix (emulsion) preparation}

For the fat-based matrix, emulsions were prepared with different fat content $(0,2.5$, and $5 \% \mathrm{v} / \mathrm{v})$. The menhaden fish oil was mixed with Milli-Q water and $0.5 \%(\mathrm{v} / \mathrm{v})$ of the emulsifier Tween 20 by using an Ultra-turrax (IKA Werke GmbH \& Co. KG) at $9500 \mathrm{rpm} \mathrm{min}^{-1}$ for $2 \mathrm{~min}$. The emulsion was subsequently homogenized using a homogenizer (Delta Instruments) for $10 \mathrm{~min}$ at 120 bar to avoid creaming.

\subsubsection{Viscosity measurement of the fat or protein-based food matrix}

Anton Paar Rheometer MCR301 (Rheology Rheometers) equipped with a double gap concentric cylinder DG26,7 (titanium) was used to measure the rheological properties of the food matrix (water, methycellulose-, protein-based matrix) with a steady shear rate of $0.1-1000$ $\mathrm{s}^{-1}$ at 5,10 and $20{ }^{\circ} \mathrm{C}$ with a gap of $57 \mu \mathrm{m}$. The relationship between viscosity and shear rate under steady flow conditions was presented.

\subsection{Determination of AITC concentration in the headspace and food matrix}

Defatted mustard seeds $(0.1 \mathrm{~g})$ were placed inside a small self-made tea bag with a cord. Samples were rehydrated by completely submerging them in Milli-Q water for $5 \mathrm{~s}$ and then immediately placed in $10 \mathrm{~mL} \mathrm{GC}$ vials containing $1 \mathrm{~mL}$ of the food matrix and then closed immediately. The samples were stored in the fridge at 5 and $10{ }^{\circ} \mathrm{C}$. The AITC concentration in the headspace and food matrix was then measured at 3,6 , $24,27,30,48,51,54$, and $72 \mathrm{~h}$. The experimental setup is depicted in Figure A1 Supplementary data.

The headspace analysis of AITC was consequently performed via Gas Chromatography - Flame Ionization Detection (GC-FID) (Thermo-Scientific Focus GC), using direct injection. The method and software used for the headspace measurement in this study was according to the method described in the previous study (Bahmid et al., 2020a).

For measurement of the initial AITC concentration in ground mustard seeds and the AITC concentration in the protein- and fat-based food matrix, Gas Chromatography - Flame Ionization Detection (GCFID) (Thermo-Scientific Focus GC) connected to an autosampler (Thermo-Scientific, TriPlus Autosampler) were used. Ground defatted mustard seeds $(0.1 \mathrm{~g})$ or fat- or protein-based matrices $(0.1 \mathrm{~mL})$ were placed in a $2 \mathrm{~mL}$ Eppendorf tube containing $1500 \mu \mathrm{L}$ hexane, then centrifuged (Centrifuge $5430 \mathrm{R}$, Eppendorf) for $5 \mathrm{~min}$ at $2627 \mathrm{~g}$ at $20^{\circ} \mathrm{C}$ (Marton and Lavric, 2013). Thereafter, the supernatant was filtered using a syringe filter (Phenex ${ }^{\text {TM}}$-PTFE $15 \mathrm{~mm}$ syringe filters $0.45 \mu \mathrm{m}$ ) and collected in a brown vial. The filtered supernatants $(1 \mu \mathrm{L})$ were injected in the GC apparatus set as described in the method in the previous study (Bahmid et al., 2020a). Data processing was performed using Xcalibur software (Thermo Fischer Scientific). To calculate the concentration of AITC in the headspace, ground mustard seeds, and food matrix, the calibration was quantified using pure AITC (Allyl isothiocyanate, 97\%) dissolved in Hexane, with the range of used concentrations 1 ppm-1000 ppm.

For modelling purposes, all AITC concentrations were expressed in $\mathrm{mol} / \mathrm{m}^{3}$ ( $\mathrm{mol}$ in a volume of mustard particles or headspace or food matrix). Each dataset was obtained by analyzing samples in duplicate and expressed as the mean values \pm standard deviations (SD).

\subsection{Building up the reaction and mass transfer pathway}

Possible mechanisms of AITC reactions and mass transfers in ground mustard seeds, headspace, and food matrix are given in Fig. 1a. The mechanisms of AITC formation, release, and degradation in the ground mustard seeds and the headspace, which are indicated by a white and 


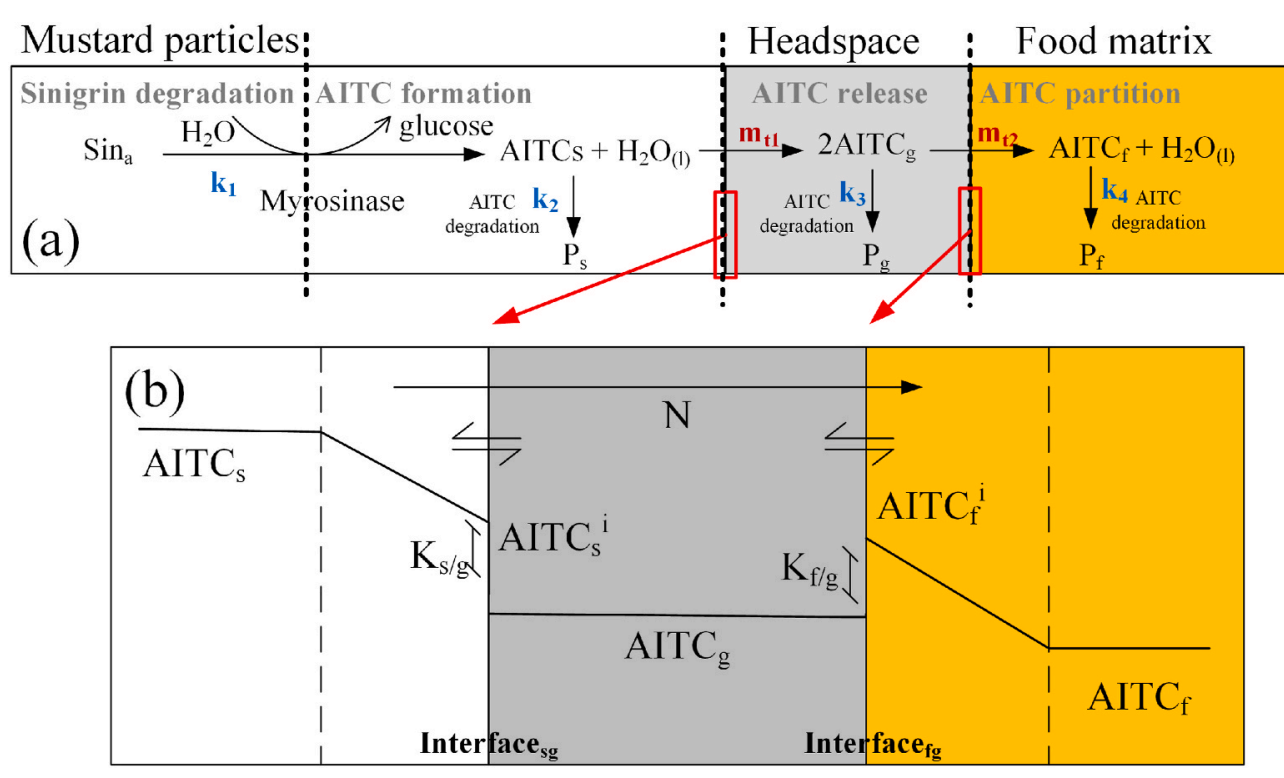

Fig. 1. (a) The proposed mechanism of the reaction and mass transfer of allyl isothiocyanates (AITC) in the packaging containing food matrix, (b) the specific mass transfer pathway in all phases; ground mustard particles (white), headspace (space grey), and food matrix (dark yellow). $\mathrm{N}$ is molar flux, $\mathrm{k}_{1-4}$ are the degradation rate constants in each phase, $\mathrm{P}_{\mathrm{s}}, \mathrm{P}_{\mathrm{g}}$, and $\mathrm{P}_{\mathrm{f}}$ are AITC breakdown products in each phase, $K_{S}$ / $\mathrm{g}$ and $\mathrm{K}_{\mathrm{f} / \mathrm{g}}$ are partition coefficients between phases, and $\mathrm{m}_{\mathrm{t} 1}$ and $\mathrm{m}_{\mathrm{t} 2}$ are mass transfer coefficients. The figure was modified and improved from Bahmid et al. (2021). (For interpretation of the references to color in this figure legend, the reader is referred to the Web version of this article.) grey color respectively in Fig. 1, were built upon the previous study (Bahmid et al., 2021). With the presence of a food matrix which is indicated with dark yellow in Fig. 1, AITC is subsequently absorbed in the food matrix where AITC is also degraded due to the nucleophilic attack of water on its isothiocyanate group $(-\mathrm{N}=\mathrm{C}=\mathrm{S}$ ) (Luang-In and Rossiter, 2015; Ohta et al., 1995). Fig. 1b shows the scheme of AITC interfacial mass transfer from ground mustard seeds into the food matrix.

The multiresponse kinetic model for the proposed mechanism was an extension of the multiresponse kinetic model developed in the previous study (Bahmid et al., 2021) that described the rate of different steps of the sinigrin degradation, AITC formation, and AITC release as following

$\frac{d\left[\sin _{t o t}\right]}{d t}=-k_{1}\left[\operatorname{Sin}_{a}\right]=-k_{1}\left[\operatorname{Sin}_{t o t}-\operatorname{Sin}_{i}\right]$

$\left.\frac{d\left[\operatorname{AITC}_{s}\right]}{d t}\right|_{f}=k_{1}\left[\operatorname{Sin}_{a}\right]=k_{1}\left[\operatorname{Sin}_{t o t}-\operatorname{Sin}_{i}\right]$

$\left.\frac{d\left[\operatorname{AITC}_{s}\right]}{d t}\right|_{m t 1}=-\frac{m_{t 1} A_{1}}{V_{s}}\left[\operatorname{AITC}_{s}-\operatorname{AITC}_{g} K_{s / g}\right]$

$\left.\frac{d\left[\operatorname{AITC}_{g}\right]}{d t}\right|_{m t 1}=\frac{m_{t 1} A_{1}}{V_{g}}\left[\operatorname{AITC}_{s}-A I T C_{g} K_{s / g}\right]$

$\left.\frac{d\left[\operatorname{AITC}_{s}\right]}{d t}\right|_{d s}=-k_{2}\left[\operatorname{AITC}_{s}\right]\left[\mathrm{H}_{2} \mathrm{O}_{s}\right]$

$\left.\frac{d\left[\operatorname{AITC}_{g}\right]}{d t}\right|_{d g}=-k_{3}\left[\operatorname{AITC}_{g}\right]^{2}$

where $\sin _{\text {tot }} \sin _{\mathrm{i}}$, and $\sin _{\mathrm{a}}$ are the concentration of total sinigrin, inaccessible and accessible sinigrin $\left(\mathrm{mol} / \mathrm{m}^{3}\right)$, respectively; AITC and V are AITC concentrations $\left(\mathrm{mol} / \mathrm{m}^{3}\right)$ and volume of each phase $\left(\mathrm{m}^{3}\right)$, respectively, and the subscripts $s$ and $g$ denote seed particles and gas phase, respectively; $t$ is degradation time (h); and $k_{1}, k_{2}$, and $k_{3}$ are the rate constant of sinigrin degradation and AITC formation $\left(\mathrm{h}^{-1}\right)$ and the rate constants of AITC degradation in the seeds and headspace, respectively $\left(\mathrm{m}^{3} / \mathrm{mol} . \mathrm{h}\right) ; \mathrm{H}_{2} \mathrm{O}_{\mathrm{s}}$ is the amount of water per volume of the ground seeds $\left(\mathrm{mol} / \mathrm{m}^{3}\right) ; \mathrm{K}_{\mathrm{s} / \mathrm{g}}$ is the partition coefficient of the partition of the concentration of AITC between the ground seeds $\left(\right.$ AITC $_{s}$ ) and headspace $\left(\right.$ AITC $\left._{g}\right) ; m_{t 1}$ is the mass transfer coefficient $(\mathrm{m} / \mathrm{h})$ of AITC release from ground seeds into headspace; $A_{1}$ is the surface area of the interface of mustard particles $\left(\mathrm{m}^{2}\right)$.

In this study, the development of the kinetic model focused on the AITC absorption in the food matrix. The absorption of AITC was determined by the mass transfer coefficient $\left(\mathrm{m}_{\mathrm{t} 2}\right)$. The mass transfer rate of AITC in the headspace and the food matrix is described by the following equations;

$\left.\frac{d\left[\operatorname{AITC}_{f}\right]}{d t}\right|_{m t 2}=\frac{m_{t 2} \cdot A_{2}}{V_{f}}\left[\operatorname{AITC}_{g} K_{f / g}-A I T C_{f}\right]$

$\left.\frac{d\left[\operatorname{AITC}_{g}\right]}{d t}\right|_{m t 2}=-\frac{m_{t 2} A_{2}}{V_{g}}\left[\operatorname{AITC}_{g} K_{f / g}-\operatorname{AITC}_{f}\right]$

where $\mathrm{K}_{\mathrm{f} / \mathrm{g}}$ is the partition coefficient between the concentration of AITC in the food matrix $\left(\mathrm{AITC}_{\mathrm{f}}\right)$ and the headspace $\left(\mathrm{AITC}_{\mathrm{g}}\right.$ ); the subscript $\mathrm{f}$ denotes the food matrix phase; $\mathrm{m}_{\mathrm{t} 2}$ is mass transfer coefficient $(\mathrm{m} / \mathrm{h})$ from headspace into food matrix; $A_{2}$ is the surface area $\left(\mathrm{m}^{2}\right)$ of the interface of food matrix.

In the food matrix phase, the AITC can be degraded due to the attack of the hydroxyl groups of water on the sulfhydryl groups of AITC. The amount of water in the food matrix is considered to remain constant over time, the AITC degradation can be described with a pseudo-first-order reaction. With the amount of water $\left(\mathrm{H}_{2} \mathrm{O}_{\mathrm{f}}\right)$ is known, the equation can be described as the following:

$\left.\frac{d\left[\operatorname{AITC}_{g}\right]}{d t}\right|_{d_{f}}=-k_{4}\left[\operatorname{AITC}_{f}\right]\left[H_{2} O_{f}\right]$

where $\mathrm{k}_{4}$ is the AITC degradation rate constant in the food matrix $\left(\mathrm{m}^{3} /\right.$ mol.h), and $\mathrm{H}_{2} \mathrm{O}_{\mathrm{f}}$ is the amount of water per volume of the food matrix $\left(\mathrm{mol} / \mathrm{m}^{3}\right)$.

\subsection{Multiresponse kinetic modelling approach and software system used}

The proposed pathway in Fig. 1a contains four steps; sinigrin degradation, AITC formation and degradation in ground seeds, AITC release and degradation in the headspace, and AITC absorption and degradation in the food matrix. These mechanisms were described with the set of equations below, which were combined equations from Eq. (1)- Eq. (9).

$\left.\frac{d\left[\operatorname{Sin}_{\text {tot }}\right]}{d t}\right|_{\text {sum }}=\frac{d\left[\operatorname{Sin}_{\text {tot }}\right]}{d t}$ 


$$
\begin{aligned}
& \left.\frac{d\left[\text { AITC }_{s}\right]}{d t}\right|_{\text {sum }}=\left.\frac{d\left[\text { AITC }_{s}\right]}{d t}\right|_{f}+\left.\frac{d A I T C_{s}}{d t}\right|_{m t 1}+\left.\frac{d\left[\text { AITC }_{s}\right]}{d t}\right|_{d s} \\
& \left.\frac{d\left[\text { AITC }_{g}\right]}{d t}\right|_{\text {sum }}=\left.\frac{d A I T C_{g}}{d t}\right|_{m_{t 1}}+\left.\frac{d\left[A I T C_{g}\right]}{d t}\right|_{d_{g}}+\left.\frac{d A I T C_{g}}{d t}\right|_{m_{t 2}} \\
& \left.\frac{d\left[\text { AITC }_{f}\right]}{d t}\right|_{\text {sum }}=\left.\frac{d A I T C_{f}}{d t}\right|_{m_{t 2}}+\left.\frac{d\left[A I T C_{g}\right]}{d t}\right|_{d_{f}}
\end{aligned}
$$

These differential equations were simultaneously fitted to the experimental data of AITC concentrations in the headspace and the food matrix. The estimated parameters consisted of reaction rate constants $\left(\mathrm{k}_{1}, \mathrm{k}_{2}, \mathrm{k}_{3}\right.$, and $\left.\mathrm{k}_{4}\right)$, mass transfer coefficients $\left(\mathrm{m}_{\mathrm{t} 1}\right.$ and $\left.\mathrm{m}_{\mathrm{t} 2}\right)$, partition coefficients $\left(\mathrm{K}_{\mathrm{s} / \mathrm{g}}\right.$ and $\mathrm{K}_{\mathrm{f} / \mathrm{g}}$ ), and initial sinigrin content in the ground seeds. The set of differential equations and the estimation of the unknown parameters were solved by using Athena Visual Studio software (v.14.2) (AthenaVisual Inc.). In the parameter estimation solver control panel, standard options were used, the convergence criterion $(=0.01)$, the maximum number of iterations $(=30)$, estimation solver options (non-linear least-squares, gradient calculation (forward differences scheme), and relative perturbation step size $\left(10^{-3}\right)$. The software estimated 58 parameters, from 12 experiments and 32 responses, using 384 data points in total. The goodness of fit of the kinetic models was then evaluated by examining the R-square of parity plots of predicted vs observed data, correlations, and the standard deviations of the parameters.

The parameters $\mathrm{k}_{1}, \mathrm{k}_{2}, \mathrm{k}_{3}, \mathrm{~m}_{\mathrm{t} 1}$, and initial sinigrin $\left(\operatorname{Sin}_{0}\right)$ and initial sinigrin $\left(\right.$ AITC $\left._{0}\right)$ content, are involved in mechanisms outside the food matrix and were therefore assumed to be independent of the food matrix composition. $\operatorname{Sin}_{0}$ and $\mathrm{AITC}_{0}$ were also assumed to be independent of the temperature. The initial concentrations of AITC in the headspace and food matrix were set to zero. Other parameters and constants used in the modelling with known values are given in Table A1 Supplementary data. The assumptions corresponding to the conditions of the packaging system were given in Table A2 Supplementary data.

\subsection{Differential sensitivity analysis and principal component analysis}

A sensitivity analysis was conducted using the software Athena Visual Studio by simulating the established model for the sample of food matrix containing $2.5 \%$ protein at $5{ }^{\circ} \mathrm{C}$. The following first-order sensitivity functions were used to assess the relative effects of the model input (Rodman and Gerogiorgis, 2020),

$s(t ; \theta)=\frac{\partial y(t)}{\partial \theta}$

where $s(t ; \theta)$ is the dynamic sensitivity function of parameters $(\theta)$ on model state (y). To compare the effect of each parameter $\left(\mathrm{k}_{1}, \mathrm{k}_{2}, \mathrm{k}_{3}, \mathrm{k}_{4}\right.$, $\mathrm{mt}_{1}, \mathrm{mt}_{2}, \mathrm{k}_{\mathrm{f} / \mathrm{g}}, \mathrm{Sin}_{0}$, and $\mathrm{AITC}_{0}$ ) on sinigrin and AITC content in the packaging system, the mean squared summary for each parameter, omsqr, can be used as a means analysis by the following equation where the model has been evaluated at $\mathrm{n}$ discrete time points (Rodman and Gerogiorgis, 2020).

$\delta m s q r=\sqrt{\frac{1}{n} \sum_{t=1}^{n} s^{2}(t)}$

Principal components analysis (PCA) for the parameters of the model was conducted in IBM SPSS statistics 25 using factor analysis to show the effects of the estimated parameters on different factors. Some estimated parameters, like $\mathrm{k}_{1}, \mathrm{k}_{2}, \mathrm{k}_{3}, \mathrm{mt}_{1}, \operatorname{Sin}_{0}$ and $\mathrm{AITC}_{0}$, were excluded because these were constant variables (no effects on the fat and protein). The fat content, protein content, temperature, $\mathrm{k}_{4}, \mathrm{mt}_{2}$ and $\mathrm{K}_{\mathrm{f} / \mathrm{g}}$ were analyzed to investigate their dependence on fat content, protein content and temperature, and the correlation amongst the parameters.

\section{Results and discussion}

\subsection{Experimental results}

The AITC concentrations in the headspace and food matrix containing fat or protein in food packaging were measured. Figs. 2 and 4 show predicted and measured AITC concentration in the headspace and the protein- or fat-based matrix at 5 and $10{ }^{\circ} \mathrm{C}$. The presence of a food matrix in the food packaging system results in the partition of AITC, which was released from ground seeds, between the headspace and the food matrix. In the headspace, the AITC concentration immediately peaked in the first $6 \mathrm{~h}$, while in the food matrix the peak of AITC concentration was delayed and was reached after $24 \mathrm{~h}$. After this peak the AITC concentration reduced gradually in the headspace and the matrix. This partition behavior of volatile compounds in the headspace and food was similar as observed by Wang et al. (2020b), who investigated the partitioning of carvacrol in an antimicrobial package. A higher amount of carvacrol was observed in ground beef with higher fat content. The absorption of the volatile in the food depends on the composition of food products. According to the relation between the AITC concentration in the headspace and the food matrix containing fat and protein shown in Figure A5 in Supplementary data, a higher fat content in the food matrix caused more AITC absorbed in the food matrix, while a higher protein content caused an increasing concentration in the headspace. These effects of fat and protein on the kinetics of AITC absorption in the food matrix are discussed further in the next sections.

\subsection{Multiresponse kinetic modelling and estimated parameters}

To describe the partition of AITC between the headspace and the food matrix, the established model enumerated in Eq (10) - Eq (13) was fitted to the experimental results. The fits of the models on the experimental data are shown in Figs. 2 and 4, and Tables 1 and 2 show the estimated parameters resulted from the kinetic modelling, which are interpreted and discussed in later sections. Table 1 shows most estimated parameters was observed in low standard deviations. A parameter, $\mathrm{k}_{3}$, was estimated with an undetectable standard deviation and high correlation. The high correlation for $\mathrm{k}_{3}$ for both temperatures was related to the AITC release from the headspace, AITC absorption in the food matrix, and partition coefficients, so it could be difficult for the software to estimate the value. The correlation coefficients amongst the estimated parameters are shown in Figures A6 and A7 in Supplementary data. The correlation of the parameters was simplified by the PCA analysis in Figure A10b in Supplementary data, in which the parameters $\mathrm{k}_{4}$ and $\mathrm{mt}_{2}$ have a high correlation. Although $\mathrm{k}_{4}$ and $\mathrm{mt}_{2}$ for each sample were highly correlated $(>0.90)$, the standard deviations of the estimations of $\mathrm{k}_{4}$ and $\mathrm{mt}_{2}$ for each sample were very low. The most influencing factors influencing the sinigrin and AITC content in the packaging system were analyzed using the sensitivity analysis as shown in Figure A9 in Supplementary data. The $\mathrm{k}_{4}$ and $\mathrm{mt}_{2}$ were the main factors influencing the AITC content in the headspace, and only $\mathrm{k}_{4}$ was influencing the AITC concentration in the food matrix. Furthermore, parity plots of observed data against predicted data, which are shown in Figure A4 in Supplementary data, show a good fit of the established kinetic model fitted on the experimental data. $\mathrm{R}$ squares of the parity plots for the headspace concentration at $5{ }^{\circ} \mathrm{C}$ and $10{ }^{\circ} \mathrm{C}$ were 0.97 and 0.90 , respectively, and for the food matrix, the plots had $\mathrm{R}^{2}$ of 0.96 and 0.98 at $5{ }^{\circ} \mathrm{C}$ and $10{ }^{\circ} \mathrm{C}$, respectively. The parity plots indicate that the proposed multiresponse kinetic model gave a good description of all mechanisms of mass transfer and reactions in the food packaging system.

Therefore it can be concluded that the established model is generally applicable and the proposed mechanisms of AITC formation, release, and its partition between headspace and food matrix in the packaging system were highly acceptable for describing the experimental results. 

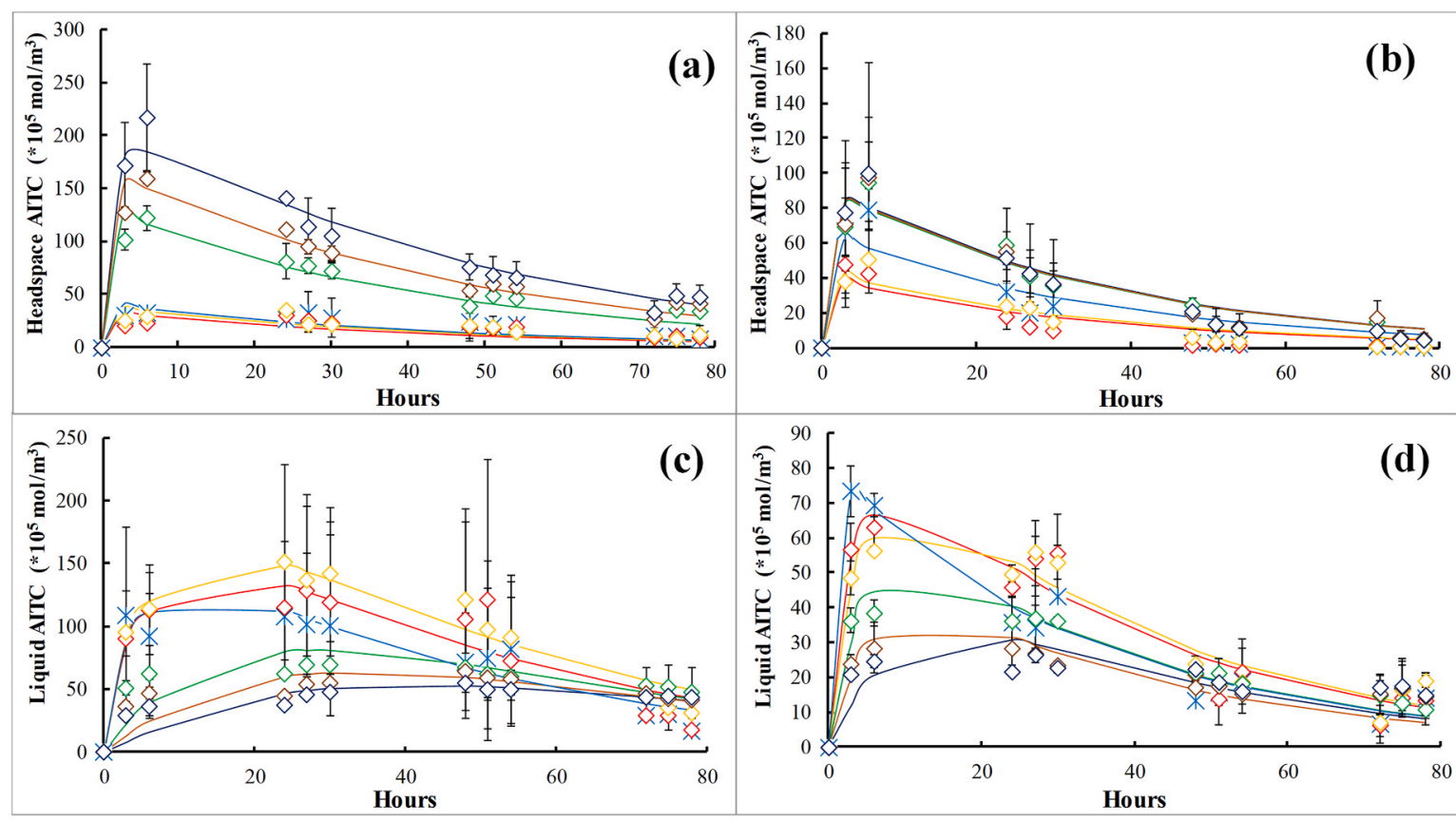

Fig. 2. The predicted data (line) and the experimental data (measurement points) of the allyl isothiocyanates (AITC) concentration in the headspace (a and b) and in

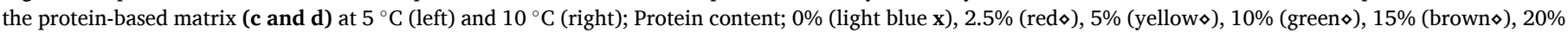
(dark blue $\diamond$. (For interpretation of the references to color in this figure legend, the reader is referred to the Web version of this article.)

Table 1

The estimated parameters ( \pm standard deviations) of the kinetic model.

\begin{tabular}{|c|c|c|c|c|c|c|c|c|c|}
\hline \multirow[t]{2}{*}{ Parameters } & \multirow[t]{2}{*}{ Temperatures } & \multicolumn{8}{|l|}{ Samples } \\
\hline & & water & $\begin{array}{l}2.5 \% \\
\text { protein }\end{array}$ & $5 \%$ protein & $10 \%$ protein & $15 \%$ protein & $\begin{array}{l}20 \% \\
\text { protein }\end{array}$ & $2.5 \%$ fat & $5 \%$ fat \\
\hline \multirow[t]{2}{*}{$\mathrm{k}_{4}\left(\mathrm{x} 10^{6} \mathrm{~m}^{3} / \mathrm{mol} . \mathrm{h}\right)$} & $5^{\circ} \mathrm{C}$ & $1.84 \pm 0.29$ & $1.28 \pm 0.18$ & $1.13 \pm 0.15$ & $0.70 \pm 0.13$ & $0.56 \pm 0.13$ & $0.41 \pm 0.13$ & $0.44 \pm 0.04$ & $0.12 \pm 0.01$ \\
\hline & $10^{\circ} \mathrm{C}$ & $14.45 \pm 2.24$ & $2.94 \pm 0.87$ & $2.32 \pm 0.64$ & $3.30 \pm 1.38$ & $2.87 \pm 1.43$ & $1.56 \pm 0.84$ & $0.49 \pm 0.09$ & $0.13 \pm 0.01$ \\
\hline \multirow[t]{2}{*}{$\mathrm{m}_{\mathrm{t} 2}\left(\mathrm{x} 10^{5} \mathrm{~m} / \mathrm{h}\right)$} & $5^{\circ} \mathrm{C}$ & $43.34 \pm 7.63$ & $38.32 \pm 6.32$ & $40.62 \pm 6.31$ & $13.86 \pm 2.30$ & $9.50 \pm 1.95$ & $6.80 \pm 1.87$ & $52.32 \pm 6.69$ & $49.51 \pm 5.68$ \\
\hline & $10^{\circ} \mathrm{C}$ & $\begin{array}{l}370.86 \pm \\
76.76\end{array}$ & $\begin{array}{l}74.56 \pm \\
20.37\end{array}$ & $\begin{array}{l}59.14 \pm \\
15.39\end{array}$ & $\begin{array}{l}57.58 \pm \\
23.45\end{array}$ & $\begin{array}{l}35.90 \pm \\
17.59\end{array}$ & $\begin{array}{l}18.90 \pm \\
9.91\end{array}$ & $\begin{array}{l}123.92 \pm \\
16.37\end{array}$ & $\begin{array}{l}138.98 \pm \\
17.38\end{array}$ \\
\hline \multirow{2}{*}{$\begin{array}{l}\mathrm{K}_{\mathrm{f} / \mathrm{g}} \\
\quad \text { (dimensionless) }\end{array}$} & $5^{\circ} \mathrm{C}$ & $16.21 \pm 2.38$ & $19.75 \pm 3.48$ & $17.90 \pm 2.87$ & $5.37 \pm 0.40$ & $4.04 \pm 0.38$ & $3.04 \pm 0.46$ & $25.52 \pm 5.82$ & $39.23 \pm 13.93$ \\
\hline & $10^{\circ} \mathrm{C}$ & $4.31 \pm 1.85$ & $8.32 \pm 1.36$ & $7.74 \pm 1.17$ & $3.70 \pm 0.34$ & $3.74 \pm 0.34$ & $3.74 \pm 0.32$ & $14.69 \pm 4.17$ & $25.18 \pm 12.70$ \\
\hline
\end{tabular}

Table 2

The estimated parameters ( \pm standard deviations) of the kinetic model assumed to be independent of the food matrix composition.

\begin{tabular}{|c|c|c|c|c|c|c|}
\hline \multirow[t]{2}{*}{ Temperatures } & \multicolumn{5}{|c|}{ Parameters } & \multirow[b]{2}{*}{$\begin{array}{l}\mathrm{AITC}_{0} \\
(\mathrm{~mol} / \\
\left.\mathrm{m}^{3}\right)\end{array}$} \\
\hline & $\begin{array}{l}\mathbf{k}_{1} \\
\left(\mathrm{x} 10^{2}\right. \\
\left.\mathrm{h}^{-1}\right)\end{array}$ & $\begin{array}{l}\mathbf{k}_{\mathbf{2}} \\
\left(\mathrm{x} 10^{3}\right. \\
\mathrm{m}^{3} / \\
\text { mol.h) }\end{array}$ & $\begin{array}{l}\mathbf{k}_{\mathbf{3}} \\
\left(\mathrm{x} 10^{6}\right. \\
\mathrm{m}^{3} / \\
\text { mol.h) }\end{array}$ & $\begin{array}{l}\mathbf{m}_{\mathrm{t} 1} \\
\left(\mathrm{x} 10^{5}\right. \\
\mathrm{m} / \mathrm{h})\end{array}$ & $\begin{array}{l}\mathrm{Sin}_{\mathbf{0}} \\
(\mathrm{mol} / \\
\left.\mathrm{m}^{3}\right)\end{array}$ & \\
\hline $5^{\circ} \mathrm{C}$ & $\begin{array}{l}2.34 \pm \\
0.17\end{array}$ & $\begin{array}{l}5.72 \pm \\
0.39\end{array}$ & $\begin{array}{l}10.46 \\
\pm 29.15\end{array}$ & $\begin{array}{l}6.05 \pm \\
1.34\end{array}$ & $\begin{array}{l}90.52 \\
\pm 5.91\end{array}$ & $\begin{array}{l}6.16 \pm \\
1.28\end{array}$ \\
\hline $10^{\circ} \mathrm{C}$ & $\begin{array}{l}2.82 \pm \\
0.18\end{array}$ & $\begin{array}{l}14.17 \\
\pm 0.91\end{array}$ & $\begin{array}{l}12.56 \\
\pm \mathrm{UD}\end{array}$ & $\begin{array}{l}7.83 \pm \\
2.42\end{array}$ & & \\
\hline
\end{tabular}

*UD $=$ undetermined standard deviations which indicates that standard deviation could not be estimated during the fitting of the model due to high correlations.

\subsection{Effects of the protein content of the food matrix on the kinetics of AITC absorption from the headspace}

Fig. 2 shows that the protein content had an inverse relation with the AITC partitioning between the headspace and food matrix. When the food matrix contains high protein content, an increased AITC concentration in the headspace and a lower concentration in the food matrix was observed at 5 and $10{ }^{\circ} \mathrm{C}$. An interesting result was that increasing the protein content from $0 \%$ up to $5 \%$ resulted in increasing AITC concentrations in the food matrix, whereas further increasing the protein content $(>5 \%)$ resulted in a decrease in the AITC concentration in the food matrix. Fig. 2c and d shows that AITC was able to penetrate quickly to the food matrices containing low protein contents $(<5 \%)$, but AITC was then degraded faster in the water at 5 and $10{ }^{\circ} \mathrm{C}$, compared to food matrix containing protein. Furthermore, Table 1 shows the increased protein content in the food matrix resulted in a reduced estimated mass transfer coefficient from headspace to food matrix $\left(\mathrm{m}_{\mathrm{t} 2}\right)$, for temperatures 5 and $10{ }^{\circ} \mathrm{C}$. The lower AITC concentration observed for the package containing the higher-protein food matrix could be caused by the increased viscosity of the high protein food matrices slowing down the absorption into the food matrix. According to the viscosity of the protein-food matrix shown in Figure A2 in Supplementary data, the higher protein caused an increase in viscosity of the matrix. This is logical because the high volatile compounds, like AITC, are hardly resistant from the gas phase and the absorption in the liquid is thus limited (Ammari and Schroen, 2018). This effect of viscosity on volatile absorption was also described by Li et al. (2012) that the gels with higher viscosities provide stronger binding power which limited the volatiles to diffuse into the gel (highly viscous solution).

The effect of viscosity on AITC absorption was also confirmed in Figure A3 in Supplementary data. An increasing concentration of 
methylcellulose increased the viscosity of the matrix (Figure A3a), and the presence of methylcellulose in the food matrix caused a lower AITC concentration in the food matrix and a higher concentration in the headspace (Figures A3a and A3b). Although the viscosity of the food matrix containing $2.5 \%$ and $5 \%$ methylcellulose shows a clear difference, which was around 100 and $1000 \mathrm{mPa} / \mathrm{s}$, respectively, the difference of AITC concentration in the headspace was not very clear. Interestingly, a lower AITC absorption was observed in the food matrix with $5 \%$ methylcellulose, which means the viscosity slowed the absorption of AITC into the food matrix. These results confirm the effect of viscosity in the food matrix on the AITC absorption, influencing the AITC partitioning between and food matrix.

Furthermore, Table 1 shows that increased protein in the matrix resulted in decreased AITC degradation rate $\left(\mathrm{k}_{4}\right)$ and partition coefficient $\left(\mathrm{K}_{\mathrm{f} / \mathrm{g}}\right)$. The package containing the low-protein food matrix $(<5 \%)$ had a higher $\mathrm{K}_{\mathrm{f} / \mathrm{g}}$ than the package with only water at 5 and $10{ }^{\circ} \mathrm{C}$. This result confirmed the obtained result as shown in Fig. 2, in which the package with low-protein $(<5 \%)$ food matrix contained higher AITC concentration in the matrix and lower headspace concentration, compared to the package with water- or high-protein- $(>5 \%)$ food matrix (Fig. 2). These results could be related to the interactions between AITC and protein. When AITC was absorbed by the protein-food matrix, AITC subsequently interacts with the free water molecules and interact with the protein as shown in Fig. 3a. The effect of protein is thus twofold: It increases the AITC absorption in the food by binding and stabilizing
AITC, but at the same time it slows down the absorption rate due to the increase of the viscosity of liquid food matrices.

The AITC in the solution can be present in two forms: "unbound AITC" present in the free water of the solution and "bound AITC" interacting with protein (Keppler et al., 2017). For the package containing water, AITC was only partitioned to the headspace and water phase. For the package with the protein-based matrix, the AITC absorbed in the matrix interacted with protein and the free water molecules between the protein molecules. The matrix with low protein content $(<5 \%)$ will result in only weak interaction between protein molecules, so the absorbed AITC can strongly bind the high-affinity binding sites of protein and, at the same time, the free water molecule (Landy et al., 1995). The strong interaction between AITC and protein and its interaction with the free water molecule caused the $\mathrm{K}_{\mathrm{f} / \mathrm{g}}$ between headspace and low-protein food matrix to be higher than $\mathrm{K}_{\mathrm{f} / \mathrm{g}}$ of the packaged with water- and higher protein-food matrix. Whilst, the high protein food matrix containing a strong interactions between protein molecules causes the volatile only binding the free water molecules (Landy et al., 1995; Nahon et al., 2000), consequently, the thermodynamic equilibrium conditions were determined between the volatile-freely interacting water and headspace (Ammari and Schroen, 2018). These results was also confirmed by the Keppler et al. (2017) that an increasing ratio of WPI to AITC concentration resulted in a decrease of AITC molecules bound to WPI proteins. Furthermore, the interactions between AITC and free water molecule or protein was also relevant to the AITC degradation
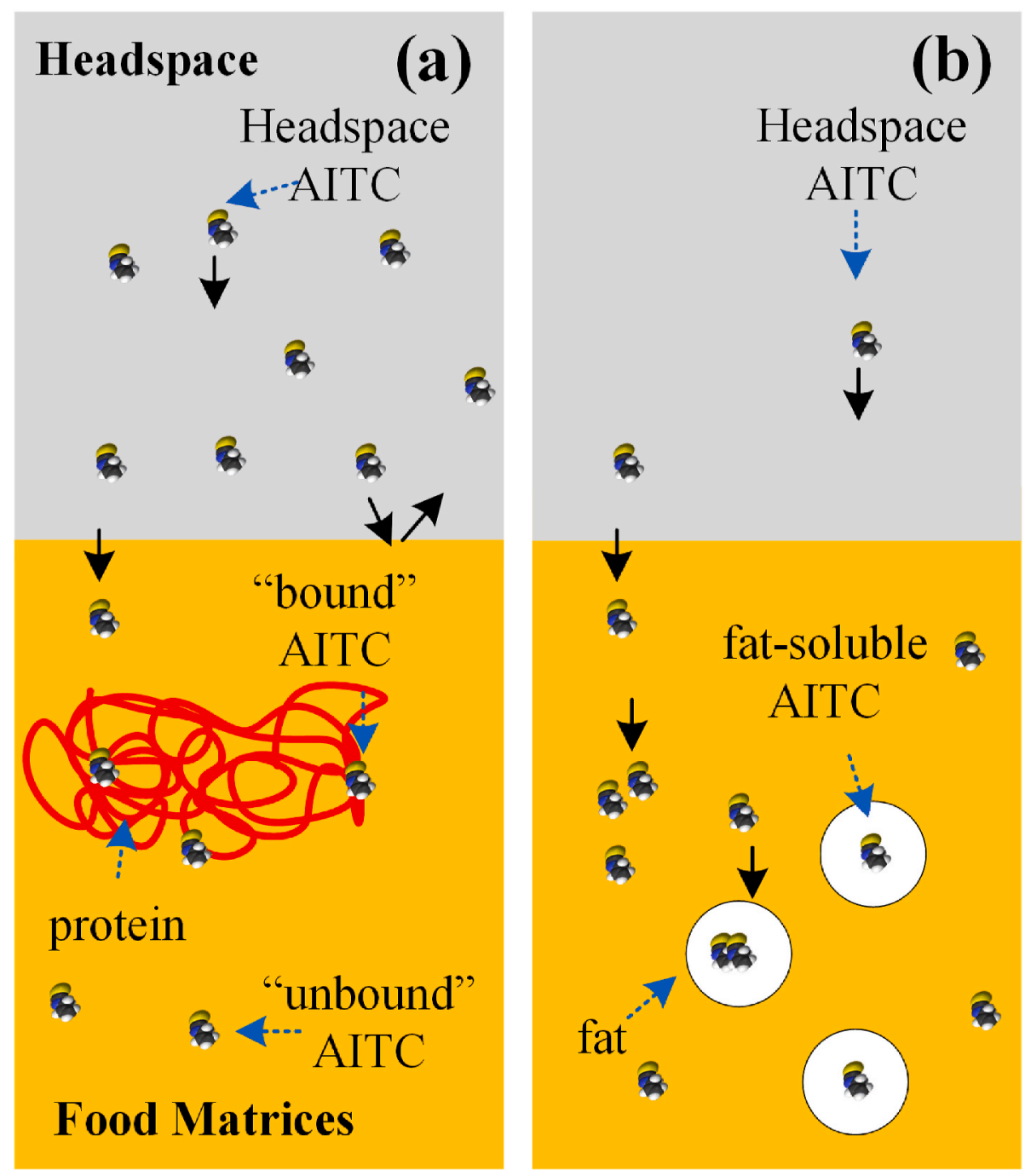

Fig. 3. The schematic allyl isothiocyanates (AITC) partition into (a) protein- and (b) fat-based food matrix in the packaging system. 

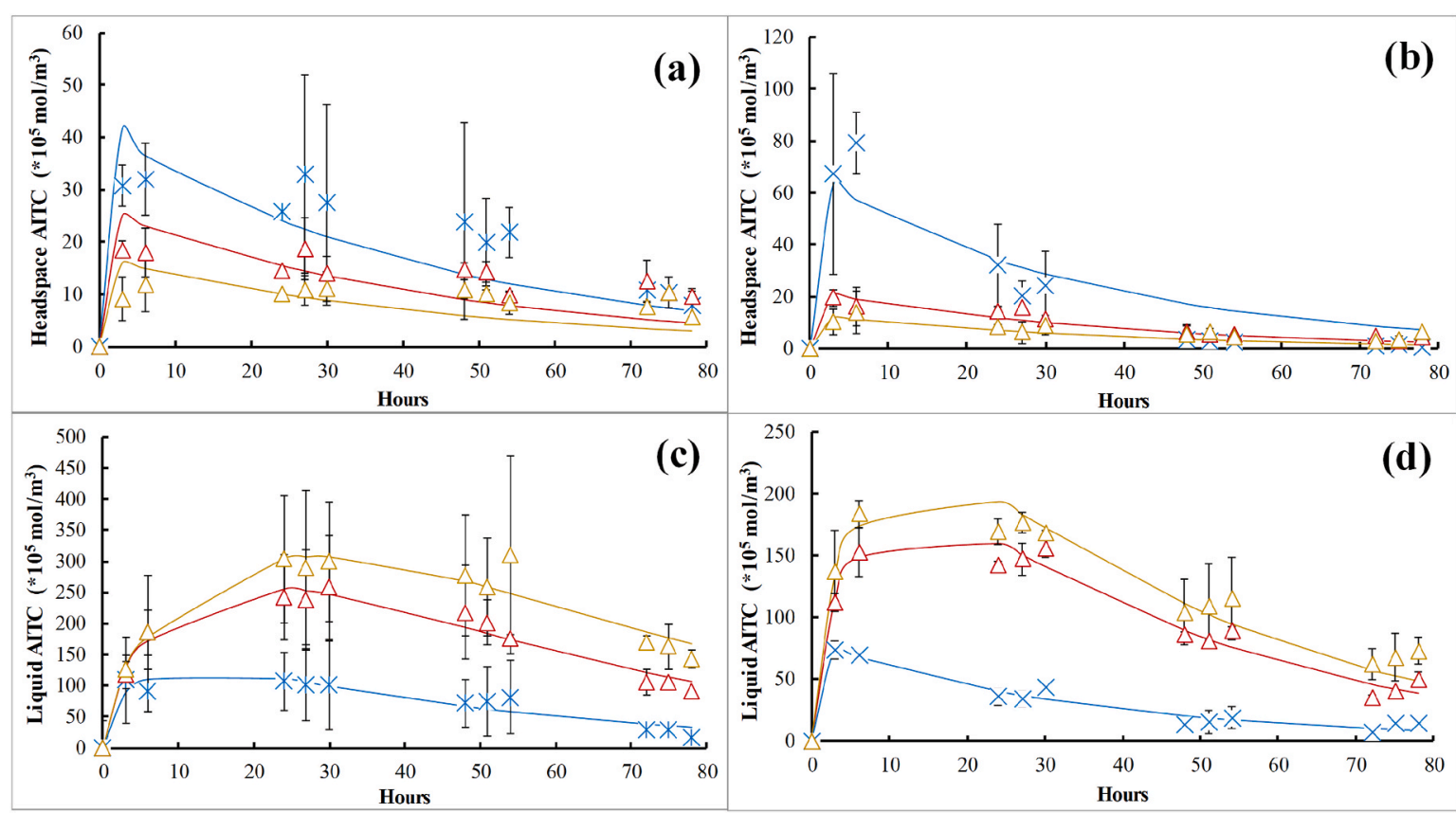

Fig. 4. The predicted data (line) and the experimental data (plot) of the allyl isothiocyanates (AITC) concentration in (a and b) the headspace and (c and d) the fatbased matrix at $5{ }^{\circ} \mathrm{C}$ (left) and $10{ }^{\circ} \mathrm{C}$ (right); Fat content; $0 \%$ (light blue $\mathbf{x}$ ), $2.5 \%$ (red $\Delta$ ), and $5 \%$ (yellow $\Delta$ ). (For interpretation of the references to color in this figure legend, the reader is referred to the Web version of this article.)

in the protein food matrix. The AITC degraded in the food matrix was the "unbound" AITC interacted to water molecule due to its susceptibility to being attacked by nucleophiles such as $\mathrm{H}_{2} \mathrm{O},{ }^{-} \mathrm{OH},{ }^{-} \mathrm{SH}$, and ${ }^{-} \mathrm{NH}_{2}$ groups (Cejpek et al., 2000; Liu and Yang, 2010). Therefore, more free water molecules available in the food matrix caused faster AITC degradation.

Concerning the antimicrobial activity, higher AITC concentration in the headspace of packaging due to the higher viscosity of the food matrix will be beneficial to inhibit spoilage bacteria growing on the surface of the packaged foods. In the protein-based matrix, although the "unbound" AITC is less stable, this AITC is expected to potentially have growth inhibitory effects on microorganisms present in the food matrix, whereas the "bound" AITC has no antimicrobial effects (Keppler et al., 2017). Further studies are required to investigate the antimicrobial effects of AITC released from ground mustard seeds on (model) food containing different protein content.

\subsection{Effects of fat content of the food matrix on the kinetics of AITC absorbed from the headspace}

Increased fat content leads to a lower AITC concentration in the headspace and higher concentration in the fat-based matrix (Fig. 4). Table 1 shows that the higher fat content strongly resulted in an increase in the estimated $\mathrm{m}_{\mathrm{t} 2}$ and $\mathrm{K}_{\mathrm{f} / \mathrm{g}}$ at 5 and $10{ }^{\circ} \mathrm{C}$, but a decrease in $\mathrm{k}_{4}$. This result was related to the solubility of AITC in the fat phase. As shown in Fig. 3b, when AITC was absorbed by the fat-based matrix, the AITC subsequently partitions between the aqueous phase and lipid phase of the matrix. The fat phase contains a higher AITC concentration than the aqueous phase due to the high solubility of AITC in the fat phase (Li et al., 2015). The same result was also observed in the real food. Wang et al. (2020b) found that the ground beef with higher fat content contained higher amount of carvacrol. The solubility of AITC in the fat phase also caused better stability of AITC concentrations in the fat-based matrix. As shown in Table 1, the AITC degradation in the fat-based matrix became lower with increasing fat content. The higher fat content in the food matrix caused a higher amount of AITC to diffuse to the lipid phase where the AITC is protected from nucleophilic attacks in the aqueous phase.

For its application in microbial inhibition, the higher fat content in the packaged food might have a negative impact on the effective AITC concentration that has antimicrobial activity against spoilage bacteria growing on the food. The higher AITC concentration in the lipid phase leads to less AITC concentration in an aqueous phase in the (model) food and headspace and thereby reduce its antimicrobial activity against a variety of microorganisms (Wang et al., 2020a). In a real food, the fat and proteins can form complexes and affect the microbial inhibition in the food matrix. Therefore, it is important to further study the effectiveness of the antimicrobial compounds in real food products with different food composition.

\subsection{Effects of temperature on the kinetics of AITC partition from headspace to food matrix}

The temperature had a clear effect on all estimated parameters in this study (Tables 1 and 2). The higher temperature resulted in higher estimated degradation rate constants in all phases $\left(\mathrm{k}_{1}, \mathrm{k}_{2}, \mathrm{k}_{3}\right.$, and $\left.\mathrm{k}_{4}\right)$ and AITC absorption in food matrix $\left(\mathrm{m}_{\mathrm{t} 1}\right.$ and $\left.\mathrm{m}_{\mathrm{t} 2}\right)$, and lower partition coefficient $\left(\mathrm{K}_{\mathrm{f} / \mathrm{g}}\right)$. A slower AITC degradation in the lower temperature was expected since the lower temperature improves the AITC stability in the packaging system (Fares et al., 1998; Liu and Yang, 2010; Ohta et al., 1995). The reason for the lower $\mathrm{K}_{\mathrm{f} / \mathrm{g}}$ was due to the high volatility of AITC in increasing temperature. This result was consistent with the result observed by Zhang et al. (2010), in which the higher temperature reduced the partition coefficient of AITC between olive or canola oil and air. Furthermore, the increasing temperatures weaken the binding sites between protein molecules and reduce the viscosity of the fat-based matrix (Hong et al., 2018), resulting in the observed higher mass transfer coefficients (Table 1), indicating the quick AITC absorption in the protein- and fat-based matrix at the higher temperature.

\section{Conclusion}

In this study, the effects of the food compositions and temperature on AITC partitioning in the food packaging system were investigated. The 
amount of fat and proteins present in the food matrix has a strong influence on the partitioning of AITC between the food matrix and the headspace. The AITC concentration is more stable in the higher fatbased food matrix and a higher mass transfer coefficient from headspace to food matrix was observed. An increase in protein content increases the viscosity of the food matrix, thereby reducing the AITC penetration into the food matrix, but the complex between proteins and AITC stabilizes AITC in the food matrix. Furthermore, temperature plays an important role in the stability of AITC in the phases of food packaging. By lowering the temperatures, a higher AITC headspace concentration is obtained that can be retained for longer times. The established multiresponse kinetic model could well describe the experimental data of the release of AITC from mustard seeds into the headspace and the absorption of AITC by the water or protein- or fat-based food matrix, and AITC degradation in all phases. It is recommended to do further studies in (model) food to investigate the effect of food composition on the antimicrobial effects of AITC to extend the shelf life of packaged food. These results give a better insight into the effects of the food composition and temperature on the absorption of the compounds in different foods, helps the food industry to optimize the design of an antimicrobial package that contains the desired concentration of the antimicrobial compounds in the package headspace and in the food to inhibit the bacterial growth for an extended food shelf life.

\section{CRediT author statement}

Nur Alim Bahmid: Conceptualization, Methodology, Investigation, Data Curation, Visualization, Formal analysis, Writing - original draft, Funding acquisition. Matthijs Dekker: Software, Formal Analysis, Conceptualization, Supervision, Writing - review \& editing. Vincenzo Fogliano: Supervision, Writing - review \& editing. Jenneke Heising: Conceptualization, Supervision, Writing - review \& editing.

\section{Declaration of competing interest}

The authors declare that they have no known competing financial interests or personal relationships that could have appeared to influence the work reported in this paper.

\section{Acknowledgment}

This work is supported by the Indonesian Endowment Fund for Education (LPDP) (Grant numbers: PRJ-4174/LPDP.3/2016). Thanks to Gerieke de Groot for involvement in some parts of the experiments.

\section{Nomenclature/Abbreviation}

$\mathrm{d}=$ diameter of ground mustard seeds/mustard particles (m)

$\mathrm{A}_{1} \quad=$ the surface area of the interface mustard particles $\left(\mathrm{m}^{2}\right)$

$\mathrm{A}_{2} \quad=$ the surface area of the interface food matrix $\left(\mathrm{m}^{2}\right)=$

$\mathrm{m}_{\mathrm{s}} \quad=$ mass of mustard particles $(\mathrm{g})$

$\rho_{\mathrm{s}} \quad=$ density of mustard particles $\left(\mathrm{g} / \mathrm{m}^{3}\right)$

$\mathrm{V}_{\mathrm{vi}} \quad=$ volume of glass vial $\left(\mathrm{m}^{3}\right)$

$\mathrm{V}_{\mathrm{g}} \quad=$ volume of headspace $\left(\mathrm{m}^{3}\right)$

$\mathrm{V}_{\mathrm{s}} \quad=$ volume of mustard particles $\left(\mathrm{m}^{3}\right)$

$\mathrm{V}_{\mathrm{f}} \quad=$ volume of food matrix $\left(\mathrm{m}^{3}\right)$

AITC $_{0}=$ Initial concentration of AITC in the mustard seeds particles $\left(\mathrm{mol} / \mathrm{m}^{3}\right)$

AITC $_{\mathrm{s}}=$ concentration of AITC in the mustard seeds particles (mol/ $\mathrm{m}^{3}$ )

AITC $_{s}^{i}=$ concentration of AITC at the interface of the mustard seeds particles $\left(\mathrm{mol} / \mathrm{m}^{3}\right)$

AITC $_{\mathrm{g}}=$ concentration of AITC in the headspace $\left(\mathrm{mol} / \mathrm{m}^{3}\right)$

$\operatorname{AITC}_{\mathrm{f}}^{1}=$ concentration of AITC at the interface of the food matrix $\left(\mathrm{mol} / \mathrm{m}^{3}\right)$

AITC $_{\mathrm{f}}=$ concentration of AITC in food matrix $\left(\mathrm{mol} / \mathrm{m}^{3}\right)$
$\mathrm{AITC}_{\text {tot }}=$ total concentration of AITC in the packaging system (mol/ $\mathrm{m}^{3}$ )

$\mathrm{H}_{2} \mathrm{O}_{\mathrm{s}}=$ the concentration of added water in-ground seeds $\left(\mathrm{mol} / \mathrm{m}^{3}\right)$

$\mathrm{H}_{2} \mathrm{O}_{\mathrm{f}}=$ the concentration of added water in-food matrix $\left(\mathrm{mol} / \mathrm{m}^{3}\right)$

$\mathrm{N}=$ molar flux $\left(\mathrm{mol} / \mathrm{m}^{2} \mathrm{~h}\right)$

$\mathrm{m}_{\mathrm{t} 1}=$ mass transfer coefficient from mustard particles into headspace $(\mathrm{m} / \mathrm{h})$

$\mathrm{m}_{\mathrm{t} 2}=$ mass transfer coefficient from headspace into food matrix $(\mathrm{m} / \mathrm{h})$

D $\quad=$ average diffusion coefficient of free volatile seeds $\left(\mathrm{m}^{2}\right)$

$\mathrm{t} \quad=$ time (h)

$\mathrm{Sin}_{\mathrm{o}} \quad=$ Initial sinigrin content in mustard particles $\left(\mathrm{mol} / \mathrm{m}^{3}\right)$

$\mathrm{Sin}_{\text {tot }}=$ total sinigrin content in the mustard particles $\left(\mathrm{mol} / \mathrm{m}^{3}\right)$

$\mathrm{Sin}_{\mathrm{i}} \quad=$ inaccessible sinigrin content in the mustard particles (mol/ $\mathrm{m}^{3}$ )

$\operatorname{Sin}_{\mathrm{a}} \quad=$ accessible sinigrin content in mustard particles $\left(\mathrm{mol} / \mathrm{m}^{3}\right)$

$\mathrm{s}(\mathrm{t} ; \theta) \quad=$ the dynamic sensitivity function of parameters $(\theta)$ on model state (y)

$\mathrm{k}_{1} \quad=$ rate constant of sinigrin degradation and AITC formation $\left(\mathrm{h}^{-1}\right)$

$\mathrm{k}_{2} \quad=$ rate constant of AITC degradation in the mustard particles $\left(\mathrm{h}^{-1}\right)$

$\mathrm{k}_{3}=$ rate constant of AITC degradation in the headspace $\left(\mathrm{m}^{3} /\right.$ mol.h)

$\mathrm{k}_{4} \quad=$ rate constant of AITC degradation in the food matrix $\left(\mathrm{h}^{-1}\right)$

$\mathrm{K}_{\mathrm{s} / \mathrm{g}} \quad=$ equilibrium partition coefficient ground mustard seeds and headspace (dimensionless)

$\mathrm{K}_{\mathrm{f} / \mathrm{g}} \quad=$ equilibrium partition coefficient food matrix and headspace (dimensionless)

fat $\quad=$ fat content of the seeds (\%)

PCA = principal components analysis

ps = breakdown products in the mustard particles

$\mathrm{p}_{\mathrm{g}} \quad=$ breakdown products in the headspace

$\mathrm{p}_{\mathrm{f}} \quad=$ breakdown products in the food matrix

y $\quad=$ model state

$\left.\right|_{f} \quad=$ symbol of differential equation for AITC formation in the ground mustard seeds

$\left.\right|_{\mathrm{ds}}=$ symbol of differential equation for AITC degradation in the ground mustard seeds

$\left.\right|_{\mathrm{dg}}=$ symbol of differential equation for AITC degradation in the headspace

$\left.\right|_{\mathrm{d} f}=$ symbol of differential equation for AITC degradation in the food matrix

$\left.\right|_{\mathrm{mt1}}=$ symbol of differential equation for AITC release into the headspace

$\left.\right|_{\mathrm{mt} 2}=$ symbol of differential equation for AITC absorption by food matrix

$\left.\right|_{\text {sum }} \quad=$ symbol of sum of differential equation

$\theta \quad=$ symbol for parameters

omsqr $\quad=$ mean squared summary

\section{Appendix A. Supplementary data}

Supplementary data to this article can be found online at https://doi. org/10.1016/j.jfoodeng.2021.110539.

\section{References}

Aguilar-González, A.E., Palou, E., López-Malo, A., 2015. Antifungal activity of essential oils of clove (Syzygium aromaticum) and/or mustard (Brassica nigra) in vapor phase against gray mold (Botrytis cinerea) in strawberries. Innovat. Food Sci. Emerg. Technol. 32, 181-185.

Ammari, A., Schroen, K., 2018. Flavor retention and release from beverages: a kinetic and thermodynamic perspective. J. Agric. Food Chem. 66 (38), 9869-9881.

Bahmid, N.A., Heising, J., Dekker, M., 2021. Multiresponse kinetic modelling of the formation, release, and degradation of allyl isothiocyanate from ground mustard seeds to improve active packaging. J. Food Eng. 292, 110370. 
Bahmid, N.A., Heising, J., Fogliano, V., Dekker, M., 2020a. Packaging design using mustard seeds as a natural antimicrobial: a study on inhibition of Pseudomonas fragi in liquid medium. Foods 9 (6).

Bahmid, N.A., Pepping, L., Dekker, M., Fogliano, V., Heising, J., 2020b. Using particle size and fat content to control the release of Allyl isothiocyanate from ground mustard seeds for its application in antimicrobial packaging. Food Chem. 308.

Cejpek, K., Valušek, J., Velíšek, J., 2000. Reactions of allyl isothiocyanate with alanine, Glycine, and several peptides in model systems. J. Agric. Food Chem. 48 (8), 3560-3565.

Clemente, I., Aznar, M., Silva, F., Nerín, C., 2016. Antimicrobial properties and mode of action of mustard and cinnamon essential oils and their combination against foodborne bacteria. Innovat. Food Sci. Emerg. Technol. 36, 26-33.

Cools, K., Terry, L.A., 2018. The effect of processing on the glucosinolate profile in mustard seed. Food Chem. 252, 343-348.

Dekker, M., Hennig, K., Verkerk, R., 2009. Differences in thermal stability of glucosinolates in five Brassica vegetables. Czech J. Food Sci. 27 (Special Issue), S85-S88.

Ersöz, N., Dudak, F.C., 2020. The interaction between $\beta$-Lactoglobulin and allylisothiocyanate. Food Bioscience 36, 100600.

Fares, K., Landy, P., Guilard, R., Voilley, A., 1998. Physicochemical interactions between aroma compounds and milk proteins: effect of water and protein modification. J. Dairy Sci. 81 (1), 82-91.

Hanschen, F.S., Kühn, C., Nickel, M., Rohn, S., Dekker, M., 2018. Leaching and degradation kinetics of glucosinolates during boiling of Brassica oleracea vegetables and the formation of their breakdown products. Food Chem. 263, 240-250.

Holley, R.A., Patel, D., 2005. Improvement in shelf-life and safety of perishable foods by plant essential oils and smoke antimicrobials. Food Microbiol. 22 (4), 273-292.

Hong, T., Iwashita, K., Shiraki, K., 2018. Viscosity control of protein solution by small solutes: a review. Curr. Protein Pept. Sci. 19 (8), 746-758.

Kawakishi, S., Kaneko, T., 1987. Interactions of proteins with allyl isothiocyanate. J. Agric. Food Chem. 35 (1), 85-88.

Keppler, J.K., Martin, D., Garamus, V.M., Berton-Carabin, C., Nipoti, E., Coenye, T., Schwarz, K., 2017. Functionality of whey proteins covalently modified by allyl isothiocyanate. Part 1 physicochemical and antibacterial properties of native and modified whey proteins at pH 2 to 7. Food Hydrocolloids 65, 130-143.

Keppler, J.K., Schwarz, K., 2017. Increasing the emulsifying capacity of whey proteins at acidic $\mathrm{pH}$ values through covalent modification with allyl isothiocyanate. Colloid. Surface. Physicochem. Eng. Aspect. 522, 514-524.

Keppler, J.K., Steffen-Heins, A., Berton-Carabin, C.C., Ropers, M.-H., Schwarz, K., 2018 Functionality of whey proteins covalently modified by allyl isothiocyanate. Part 2 : influence of the protein modification on the surface activity in an $\mathrm{O} / \mathrm{W}$ system. Food Hydrocolloids 81, 286-299.

Kissen, R., Rossiter, J.T., Bones, A.M., 2009. The 'mustard oil bomb': not so easy to assemble?! Localization, expression and distribution of the components of the myrosinase enzyme system. Phytochemistry Rev. 8 (1), 69-86.

Kuhn, C., von Oesen, T., Hanschen, F.S., Rohn, S., 2018. Determination of isothiocyanate-protein conjugates in milk and curd after adding garden cress (Lepidium sativum L.). Food Res. Int. 108, 621-627.

Kurek, M., Laridon, Y., Torrieri, E., Guillard, V., Pant, A., Stramm, C., Gontard, N., Guillaume, C., 2017. A mathematical model for tailoring antimicrobial packaging material containing encapsulated volatile compounds. Innovat. Food Sci. Emerg. Technol. 42, 64-72.

Landy, P., Druaux, C., Voilley, A., 1995. Retention of aroma compounds by proteins in aqueous solution. Food Chem. 54 (4), 387-392.

Li, C., Xue, F., Xu, Y., Ren, C., Pan, S., 2012. Influence of different gel complexes on flavour and colour change in Chongcai paste during storage. Food Chem. 130 (3), 632-637.

Li, Y., Teng, Z., Chen, P., Song, Y., Luo, Y., Wang, Q., 2015. Enhancement of aqueous stability of allyl isothiocyanate using nanoemulsions prepared by an emulsion inversion point method. J. Colloid Interface Sci. 438, 130-137.

Liu, T.T., Yang, T.S., 2010. Stability and antimicrobial activity of allyl isothiocyanate during long-term storage in an oil-in-water emulsion. J. Food Sci. 75 (5), C445-C451.

Luang-In, V., Rossiter, J., 2015. Stability studies of isothiocyanates and nitriles in aqueous media. Songklanakarin J. Sci. Technol. 37.

Marton, M.R., Lavric, V., 2013. A simple method for the quantification of isothiocyanates from mustard. UPB Scientific Bulletin, Series B: Chemistry and Materials Science 75, 63-72.

Nahon, D.F., Harrison, M., Roozen, J.P., 2000. Modeling flavor release from aqueous sucrose solutions, using mass transfer and partition coefficients. J. Agric. Food Chem. 48 (4), 1278-1284.

Nakano, R.T., Yamada, K., Bednarek, P., Nishimura, M., Hara-Nishimura, I., 2014. ER bodies in plants of the Brassicales order: biogenesis and association with innate immunity. Front. Plant Sci. 5, 73.

Ohta, Y., Takatani, K., Kawakishi, S., 1995. Decomposition rate of allyl isothiocyanate in aqueous solution. Biosc. Biotech. Biochem. 59 (1), 102-103.

Quintas, M., Guimarães, C., Baylina, J., Brandão, T.R.S., Silva, C.L.M., 2007. Multiresponse modelling of the caramelisation reaction. Innovat. Food Sci. Emerg. Technol. 8 (2), 306-315.

Rangkadilok, N., Nicolas, M.E., Bennett, R.N., Premier, R.R., Eagling, D.R., Taylor, P.W. J., 2002. Developmental changes of sinigrin and glucoraphanin in three Brassica species (Brassica nigra, Brassica juncea and Brassica oleracea var. italica). Sci. Hortic. 96 (1), 11-26.

Rodman, A.D., Gerogiorgis, D.I., 2020. Parameter estimation and sensitivity analysis for dynamic modelling and simulation of beer fermentation. Comput. Chem. Eng. 136, 106665.

Saladino, F., Bordin, K., Luciano, F.B., Franzón, M.F., Mañes, J., Meca, G., 2017. Antimicrobial activity of the glucosinolates. In: Mérillon, J.-M., Ramawat, K.G. (Eds.), Glucosinolates. Springer International Publishing, Cham, pp. 249-274.

Wang, L., Dekker, M., Heising, J., Fogliano, V., Berton-Carabin, C.C., 2020a. Carvacrol release from PLA to a model food emulsion: impact of oil droplet size. Food Contr. 114, 107247.

Wang, L., Heising, J., Fogliano, V., Dekker, M., 2020b. Fat content and storage conditions are key factors on the partitioning and activity of carvacrol in antimicrobial packaging. Food Packaging and Shelf Life 24, 100500.

Winther, M., Nielsen, P.V., 2006. Active packaging of cheese with allyl isothiocyanate, an alternative to modified atmosphere packaging. J. Food Protect. 69 (10), 2430-2435.

Zhang, Z.-Q., Kim, W.-T., Park, Y.-C., Chung, D., 2010. Thermodynamics of partitioning of allyl isothiocyanate in oil/air, oil/water, and octanol/water systems. J. Food Eng. 96 (4), 628-633. 